Check for updates

Cite this: RSC Adv., 2020, 10, 43533

Received 10th October 2020

Accepted 29th October 2020

DOI: $10.1039 / \mathrm{d} 0 \mathrm{ra0} 8644 \mathrm{~d}$

rsc.li/rsc-advances

\title{
Copper mediated one-pot synthesis of quinazolinones and exploration of piperazine linked quinazoline derivatives as anti- mycobacterial agents $\uparrow$
}

\author{
Satyaveni Malasala, ${ }^{a}$ Jitendra Gour, ${ }^{a}$ Md. Naiyaz Ahmad, ${ }^{b}$ Srikanth Gatadi, ${ }^{a}$ \\ Manjulika Shukla, ${ }^{\mathrm{b}}$ Grace Kaul, $^{\mathrm{b}}$ Arunava Dasgupta, ${ }^{\mathrm{b}}$ Y. V. Madhavi, ${ }^{\mathrm{a}}$ \\ Sidharth Chopra (iD) ${ }^{b}$ and Srinivas Nanduri (D) *a
}

\begin{abstract}
A facile method was developed for the synthesis of quinazolinone derivatives in a one-pot condensation reaction via in situ amine generation using ammonia as the amine source and with the formation of four new $\mathrm{C}-\mathrm{N}$ bonds in good to excellent yields. With the optimised method, we synthesized a library of piperazine linked quinazoline derivatives and the synthesized compounds were evaluated for their inhibitory activity against Mycobacterium tuberculosis. The compounds $8 \mathrm{~b}, 8 \mathrm{e}, 8 \mathrm{f}, 8 \mathrm{~m}, 8 \mathrm{n}$ and $8 \mathrm{v}$ showed potent anti-mycobacterial activity with MIC values of $2-16 \mu \mathrm{g} \mathrm{mL}^{-1}$. All the synthesized compounds follow Lipinski's rules for drug likeness.
\end{abstract}

\section{Introduction}

Nitrogen-containing heterocycles are present in a wide range of bioactive natural products and synthetic drug candidates. ${ }^{1}$ Among them, quinazolines and their derivatives represent medicinally important structural cores present in a number of drug candidates. ${ }^{2}$ They possess a wide range of biological activities including anticancer, ${ }^{3}$ antiviral, ${ }^{4}$ antitubercular ${ }^{5}$ and antibacterial ${ }^{6}$ properties.

Recently, ammonia has attracted wide attention as a costeffective and efficient nitrogen source. ${ }^{7}$ A number of homogeneous transition-metal catalysed reactions for the synthesis of organic amines using gaseous or liquid ammonia are reported. ${ }^{8,9}$ Owing to its safety and ease of handling, aqueous ammonia is even more attractive as a substrate.

In view of the medicinal and pharmacological importance of quinazolinones, several methods on the synthesis of this class of compounds have been reported. Zhan and co-workers ${ }^{10}$ in 2013 reported an interesting approach by condensation of substituted anthranilamides with different aldehydes in presence of copper oxide for the synthesis of substituted quinazolinone derivatives. In 2014, Hung and co-workers ${ }^{11}$ reported

${ }^{a}$ National Institute of Pharmaceutical Education and Research (NIPER), Hyderabad, 500037, India. E-mail: nanduri.niperhyd@gov.in; nandurisrini92@gmail.com ${ }^{b}$ Division of Microbiology, CSIR-Central Drug Research Institute, Sitapur Road, Sector 10, Janakipuram Extension, Lucknow-226031, Uttar Pradesh, India. E-mail: skchopra. 007@cdri.res.in; skchopra007@gmail.com

$\dagger$ Electronic supplementary information (ESI) available: Synthetic procedures, experimental details, spectral information $\left({ }^{1} \mathrm{H}\right.$ and ${ }^{13} \mathrm{C}$ spectra) and biological evaluation. See DOI: 10.1039/d0ra08644d synthesis of quinazolinone by using 2-bromobenzoic acid and substituted amidines as starting materials. Abe et al. ${ }^{12}$ reported the synthesis of quinazolinones by using 2 -amino benzoic acid with substituted nitriles (Scheme 1).

Tuberculosis is a transmissible disease caused by Mycobacterium tuberculosis (Mtb) complex and recognized to have high mortality rate globally ${ }^{13}$ According to WHO reports, 10 million cases were reported in the year 2017, where India is the leading country with the highest burden of TB. ${ }^{14}$ Emergence of drug-
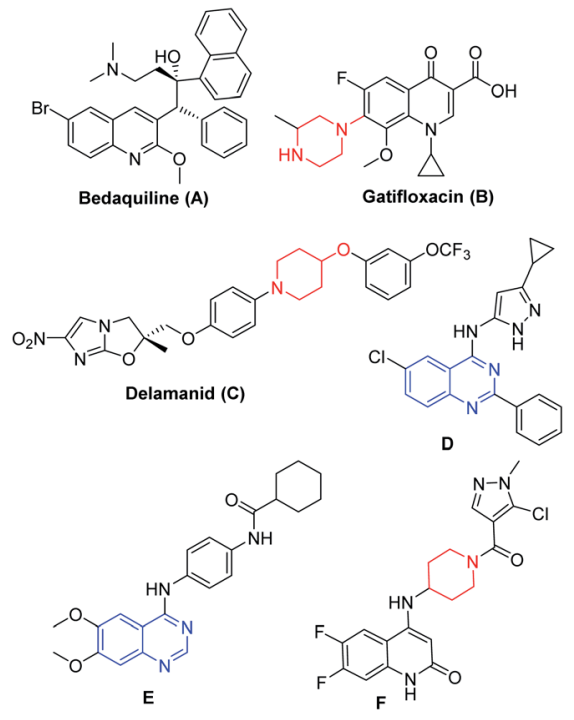

Fig. 1 Structures of mycobacterial agents. 


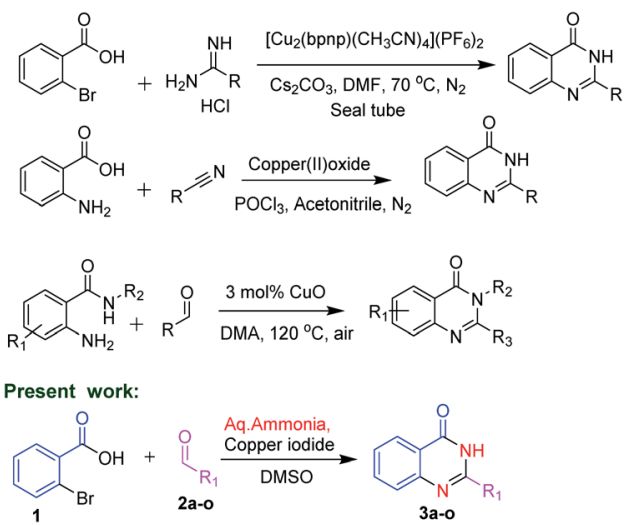

Scheme 1 Methodologies for the synthesis of quinazolinones.

resistant TB or accompanying chronic diseases like HIV and diabetes certainly limits the current treatment options and hence drives the researchers to fulfil the growing demand for new agents (Fig. 1) that are effective against drug resistant TB. ${ }^{15}$ Bedaquiline (A, Fig. 1) ${ }^{16}$ led the drug discovery efforts towards the exploration of different heterocycles as anti-mycobacterial agents. Gatifloxacin (B, Fig. 1) and delamanid (C, Fig. 1) are the $2^{\text {nd }}$ line anti-TB drugs. ${ }^{17 a, b}$ Wang et al. reported 4(aminopyrazolyl)-substituted quinazolines (D, Fig. 1) as inhibitors of protein kinases (PknA \& PknB) of Mycobacterium tuberculosis, ${ }^{17 c}$ Tran et al. developed 4-aminoquinazolines (E, Fig. 1),

Table 1 Optimization of reaction conditions ${ }^{a}$

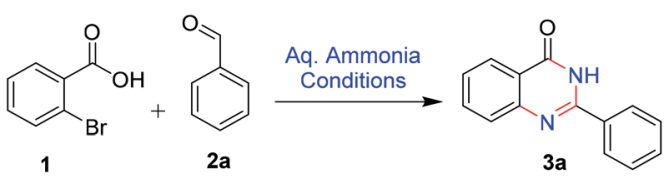

Temperature

\begin{tabular}{lllllll} 
Entry & Catalyst & Solvent & $\mathrm{O}_{2}$ & $\left({ }^{\circ} \mathrm{C}\right)$ & Time $(\mathrm{h})$ & Yield (\%) \\
\hline 1 & $\mathrm{Cu}_{2} \mathrm{O}$ & NMP & No & 80 & 24 & 0 \\
2 & $\mathrm{Cu}_{2} \mathrm{O}$ & NMP & Yes & 80 & 24 & 12 \\
3 & $\mathrm{Cu}_{2} \mathrm{O}$ & NMP & Yes & 80 & 12 & 25 \\
4 & $\mathrm{Cu}_{2} \mathrm{O}$ & NMP & Yes & 100 & 10 & 40 \\
5 & $\mathrm{CuCl}$ & NMP & Yes & 100 & 10 & $>20$ \\
6 & $\mathrm{CuCl}$ & DMSO & Yes & 100 & 10 & 24 \\
7 & $\mathrm{CuBr}$ & NMP & Yes & 100 & 10 & Trace \\
8 & $\mathrm{CuBr}$ & DMSO & Yes & 100 & 10 & $>20$ \\
9 & $\mathrm{Cu}{ }_{2} \mathrm{O}$ & DMSO & Yes & 100 & 10 & 55 \\
10 & $\mathrm{CuI}$ & DMSO & Yes & 100 & 10 & 70 \\
11 & $\mathrm{CuI}$ & ACN & Yes & 100 & 10 & Trace \\
12 & $\mathrm{CuI}$ & Toluene & Yes & 100 & 10 & Trace \\
13 & $\mathrm{CuI}$ & DMF & Yes & 100 & 10 & 40 \\
14 & $\mathrm{CuI}$ & NMP & Yes & 100 & 10 & 50 \\
15 & $\mathrm{Cu}(\mathrm{OAc})_{2}$ & DMSO & Yes & 100 & 10 & 38 \\
16 & $\mathrm{Cu}(\mathrm{OAc})_{2}$ & DMF & Yes & 100 & 12 & 26 \\
17 & $\mathrm{Cu}(\mathrm{OTf})_{2}$ & DMSO & Yes & 100 & 10 & 33
\end{tabular}

${ }^{a}$ Reaction conditions: 1 ( $\left.1 \mathrm{mmol}\right)$, aq. ammonia ( $\left.2 \mathrm{mmol}\right)$, aldehyde (1 $\mathrm{mmol})$, catalyst $(5.0 \mathrm{~mol} \%)$, solvent $(5 \mathrm{~mL})$ the reaction was performed at $100{ }^{\circ} \mathrm{C}$ for $10 \mathrm{~h}$ under oxygen atmosphere. as inhibitors of uridyl transferase activity of M. tuberculosis $\mathrm{GlmU}^{17 d}$ and Naik et al. reported the quinolone based derivatives as potent anti-mycobacterial agents (F, Fig. 1). ${ }^{17 e}$

In the present method, we have developed a copper mediated oxidative coupling of different aldehydes and 2-bromobenzoic acid, using aq. ammonia as a less expensive nitrogen source. We explored the double amination of aryl halides to the corresponding amines and also acids to amides at the same substrate. With the established method, we could successfully synthesize 4-substituted piperazine/piperidine linked C2-aryl/ heteroaryl quinazolines. The synthesized compounds were evaluated for their in vitro inhibitory activity against Mycobacterium tuberculosis H37Rv. clog $P$ values were determined using SwissADME.

\section{Results and discussion}

Direct employment of ammonia as a reagent in transition-metal catalysis is generally a challenging task. In the current optimised method, copper mediated oxidative coupling is developed between aldehydes and 2-bromobenzoic acid, using aq. ammonia as a nitrogen source. Various conditions for the conversion of $\mathbf{1}$ to $\mathbf{3}$ are studied and the results are discussed in Table 1 . We initiated our studies by using copper oxide and NMP as solvent in the absence of oxygen at $80^{\circ} \mathrm{C}$ for $24 \mathrm{~h}$ (Table 1, entry 1). The reaction did not proceed. However, we observed the formation of the product in small quantities when the

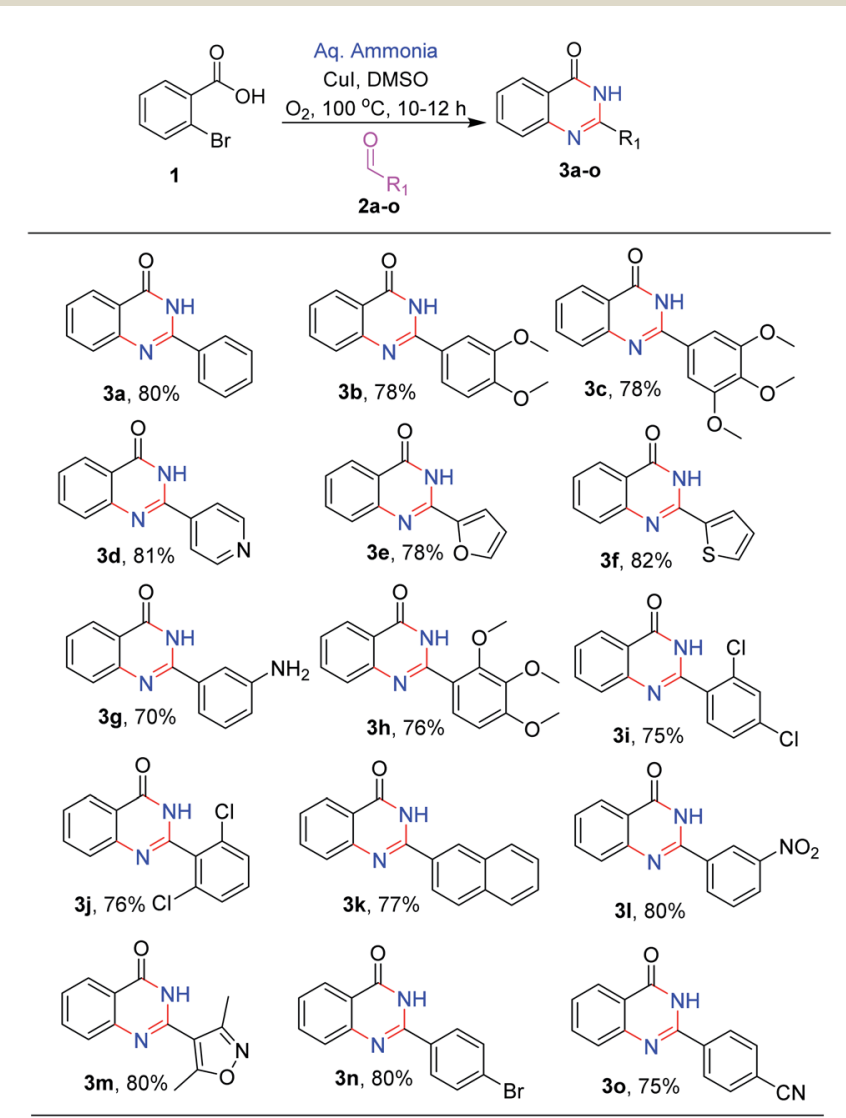

Scheme 2 Reaction scope. 


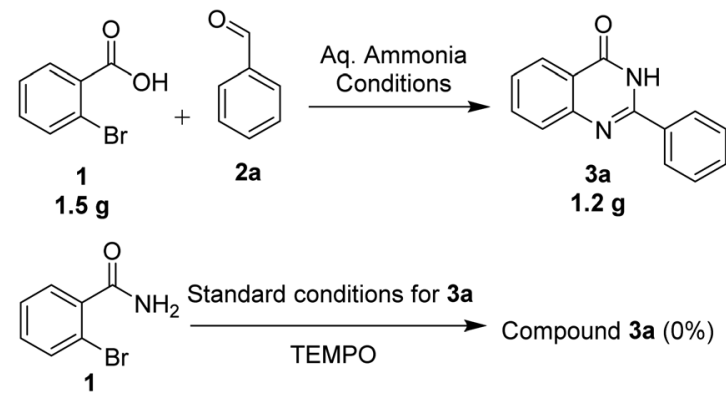

Scheme 3 Gram-scale synthesis and control experiments.

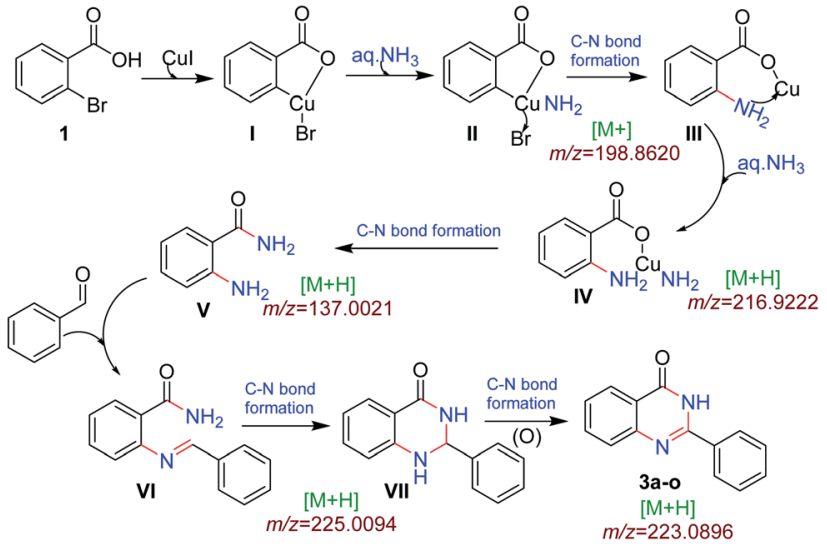

Scheme 4 Plausible reaction mechanism.

reaction was conducted in presence of oxygen (Table 1, entry 2). With changes in time and temperature we observed the product formation to be improved (Table 1, entry 3-4). Moderate yields were observed with the change of catalyst to $\mathrm{CuCl}$ or $\mathrm{CuBr}$ with DMSO or NMP as solvents (Table 1 , entry $5-8$ ). With copper

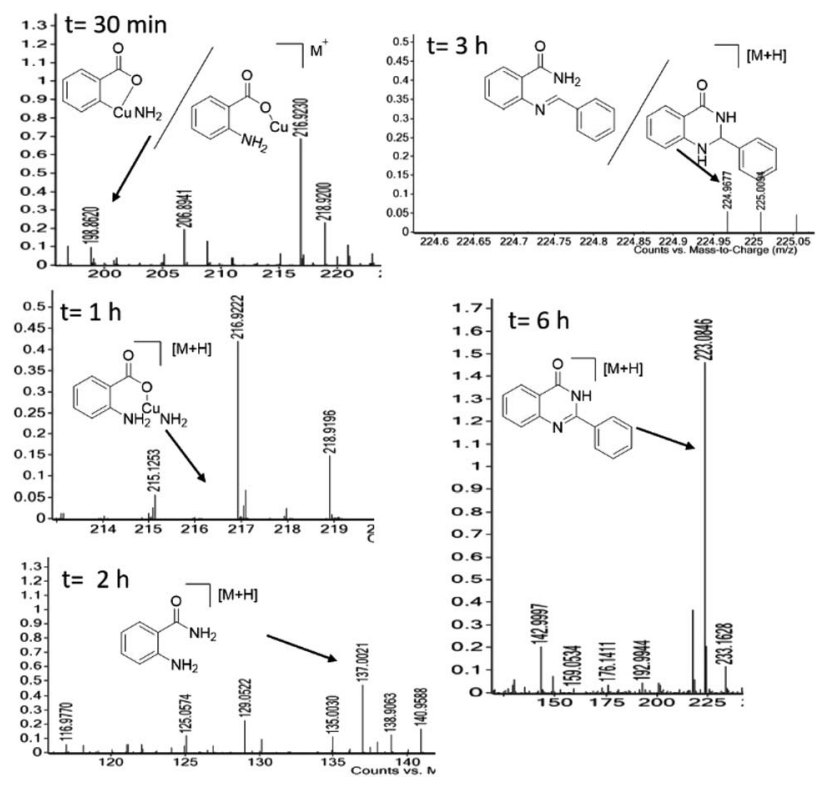

Fig. 2 ESI-MS monitoring of the reaction. oxide and $\mathrm{CuI}$ as catalysts in presence of oxygen, NMP and DMSO as the solvent, the reaction proceeded smoothly. DMSO as a solvent was found to be more favourable (Table 1, entry 910). The reaction was studied with different solvents viz., ACN, toluene, DMF and the reaction proceeded with altered yields (Table 1, entry 11-14). When the catalyst was changed to copper diacetate and coppertriflate the reaction was sluggish and resulted in low yields (Table 1, entry 15-17). The reaction was found to proceed with optimal yields with $\mathrm{CuI}$ as catalyst and DMSO as the solvent (entry 10).

After optimizing the reaction conditions, we focussed on expanding the substrate scope of this transformation and the results are summarized in (Scheme 2). It is observed that electron-donating substituents such as methoxy, amino, and methyl on 2-phenyl were well tolerated under the optimal reaction conditions, with $70-78 \%$ yields $(3 \mathbf{b}, 3 \mathbf{c}, 3 \mathbf{g}$ and $\mathbf{3 h})$. Similarly, halogen substituents like 2,4-dichloro, 2,6-dichloro

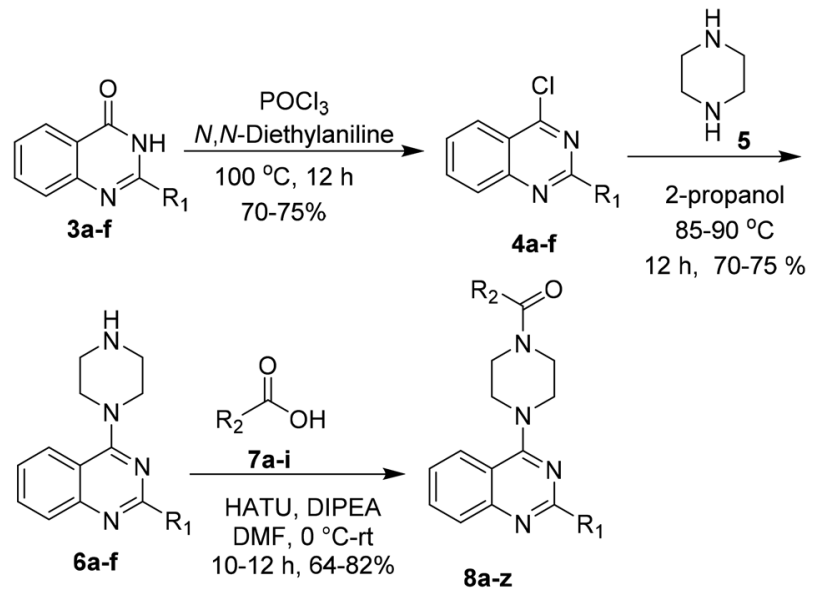

8a: $R_{1}=$ phenyl; $R_{2}=N, N$-dimethyl-4-phenyl

8b: $R_{1}=$ phenyl; $R_{2}=4$-cyanophenyl

8c: $R_{1}=$ phenyl; $R_{2}=3,5$-dimethoxyphenyl

8d: $R_{1}=$ phenyl; $R_{2}=3,4,5$-trimethoxyphenyl

8e: $R_{1}=$ phenyl; $R_{2}=2$-naphthyl

8f: $R_{1}=$ phenyl; $R_{2}=5$-chlorothiophenyl

8g: $R_{1}=$ phenyl; $R_{2}=5$-bromo-2-chlorophenyl

8h: $R_{1}=$ phenyl; $R_{2}=4$-iodophenyl

8i: $R_{1}=3,4,5$-trimethoxyphenyl; $R_{2}=4$-iodophenyl

8j: $R_{1}=3,4,5$-trimethoxyphenyl; $R_{2}=5$-bromo-2-chlorophenyl

8k: $R_{1}=3,4,5$-trimethoxyphenyl; $R_{2}=2$-naphthyl

8I: $R_{1}=3$,4-dimethoxyphenyl; $R_{2}=4$-cyanophenyl

8m: $R_{1}=3,4$-dimethoxyphenyl; $R_{2}=4$-trifluoromethylphenyl

8n: $R_{1}=4$-pyridyl; $R_{2}=\mathrm{N}, \mathrm{N}$-dimethyl-4-phenyl

8o: $R_{1}=4$-pyridyl; $R_{2}=2$-naphthyl

8p: $R_{1}=4$-pyridyl; $R_{2}=3,5$-dimethoxyphenyl

8q: $R_{1}=4$-pyridyl; $R_{2}=3,4,5$-trimethoxyphenyl

8r: $R_{1}=4$-pyridyl; $R_{2}=4$-iodophenyl

8s: $R_{1}=4$-pyridyl; $R_{2}=4$,5-dimethoxy-2-nitrophenyl

8t: $R_{1}=4$-pyridyl; $R_{2}=5$-bromo-2-chlorophenyl

$8 u: R_{1}=4$-pyridyl; $R_{2}=4$-chlorophenylacetyl

$8 v: R_{1}=2$-thiophenyl; $R_{2}=5$-bromo-2-chlorophenyl

8w: $R_{1}=2$-thiophenyl; $R_{2}=4,5$-dimethoxy-2-nitrophenyl

8x: $R_{1}=2$-thiophenyl; $R_{2}=2$-naphthyl

8y: $R_{1}=2$-furenyl; $R_{2}=4$-cyanophenyl

8z: $R_{1}=2$-furenyl; $R_{2}=4,5$-dimethoxy-2-nitrophenyl

Scheme 5 Synthetic route for the synthesis of piperazine linked quinazolines derivatives $(8 a-z)$. 
Table 2 MIC ( $\mu \mathrm{g} \mathrm{mL}^{-1}$ ) values of 2-aryl/heteroaryl quinazoline based amide derivatives $8 \mathrm{a}-\mathrm{z}$ against anti-bacterial and $M$. tuberculosis strains

\begin{tabular}{|c|c|c|c|c|c|c|c|}
\hline Sample code & $\begin{array}{l}\text { S. aureus } \\
\text { ATCC } 29213\end{array}$ & $\begin{array}{l}\text { E. coli } \\
\text { ATCC } 25922\end{array}$ & $\begin{array}{l}\text { K. pneumoniae } \\
\text { BAA } 1705\end{array}$ & $\begin{array}{l}\text { A. baumannii } \\
\text { BAA } 1605\end{array}$ & $\begin{array}{l}P . \text { aeruginosa } \\
\text { ATCC } 27853\end{array}$ & Mtb H37Rv ATCC 27294 & $\operatorname{clog} P$ \\
\hline $8 \mathbf{a}$ & $>64$ & $>64$ & $>64$ & $>64$ & $>64$ & $>64$ & 3.84 \\
\hline $\mathbf{8 b}$ & $>64$ & $>64$ & $>64$ & $>64$ & $>64$ & 16 & 3.65 \\
\hline $8 c$ & $>64$ & $>64$ & $>64$ & $>64$ & $>64$ & $>64$ & 3.9 \\
\hline 8d & $>64$ & $>64$ & $>64$ & $>64$ & $>64$ & $>64$ & 3.77 \\
\hline $8 e$ & $>64$ & $>64$ & $>64$ & $>64$ & $>64$ & 16 & 4.77 \\
\hline $8 f$ & $>64$ & $>64$ & $>64$ & $>64$ & $>64$ & 2 & 4.49 \\
\hline $8 g$ & $>64$ & $>64$ & $>64$ & $>64$ & $>64$ & $>64$ & 4.95 \\
\hline $8 h$ & $>64$ & $>64$ & $>64$ & $>64$ & $>64$ & $>64$ & 4.54 \\
\hline $8 \mathbf{i}$ & $>64$ & $>64$ & $>64$ & $>64$ & $>64$ & $>64$ & 4.45 \\
\hline $8 \mathbf{j}$ & $>64$ & $>64$ & $>64$ & $>64$ & $>64$ & $>64$ & 4.92 \\
\hline $8 k$ & $>64$ & $>64$ & $>64$ & $>64$ & $>64$ & 64 & 4.7 \\
\hline 81 & $>64$ & $>64$ & $>64$ & $>64$ & $>64$ & $>64$ & 3.56 \\
\hline $8 \mathrm{~m}$ & $>64$ & $>64$ & $>64$ & $>64$ & $>64$ & 16 & 3.56 \\
\hline $8 n$ & $>64$ & $>64$ & $>64$ & $>64$ & $>64$ & 4 & 4.76 \\
\hline 80 & $>64$ & $>64$ & $>64$ & $>64$ & $>64$ & $>64$ & 3.13 \\
\hline $8 p$ & $>64$ & $>64$ & $>64$ & $>64$ & $>64$ & $>64$ & 4.05 \\
\hline $8 q$ & $>64$ & $>64$ & $>64$ & $>64$ & $>64$ & $>64$ & 3.14 \\
\hline $8 r$ & $>64$ & $>64$ & $>64$ & $>64$ & $>64$ & $>64$ & 3.02 \\
\hline $8 s$ & $>64$ & $>64$ & $>64$ & $>64$ & $>64$ & $>64$ & 3.76 \\
\hline $8 t$ & $>64$ & $>64$ & $>64$ & $>64$ & $>64$ & 32 & 2.25 \\
\hline $8 u$ & $>64$ & $>64$ & $>64$ & $>64$ & $>64$ & $>64$ & 4.22 \\
\hline $8 v$ & $>64$ & $>64$ & $>64$ & $>64$ & $>64$ & 16 & 3.77 \\
\hline $8 w$ & $>64$ & $>64$ & $>64$ & $>64$ & $>64$ & 64 & 4.93 \\
\hline $8 x$ & $>64$ & $>64$ & $>64$ & $>64$ & $>64$ & 64 & 3.07 \\
\hline $8 y$ & $>64$ & $>64$ & $>64$ & $>64$ & $>64$ & $>64$ & 2.99 \\
\hline $8 z$ & $>64$ & $>64$ & $>64$ & $>64$ & $>64$ & $>64$ & 2.48 \\
\hline Levofloxacin & 0.125 & 0.015 & 64 & 8 & 0.5 & Not tested & \\
\hline Isoniazid & - & - & - & - & - & 0.03 & \\
\hline Rifampicin & - & - & - & - & - & 0.06 & \\
\hline
\end{tabular}

and 3-nitro are also tolerated, yielding the desired products $(3 \mathbf{j}$, $\mathbf{3 i}$ and $3 \mathbf{l})$ in good to high yields (75-79\%). Heterocycles like pyridyl, furan, thiophene and isoxazole at C-2 position (3d, 3e, 3f and $\mathbf{3 m}$ ) are also well tolerated with good to moderate yields (78-82\%). With 4-bromo and 4-cyano (3o and 3n) substituents, the reactions proceeded smoothly (Scheme 2 ).

We performed the gram scale synthesis with $1.5 \mathrm{gm}$ of 2bromo benzoic acid and benzaldehyde as the starting materials which resulted in $1.2 \mathrm{~g}$ of the final product (Scheme 3). As the reaction with TEMPO did not show the product formation, the free radical mediated mechanism is observed and conventional mechanism in one-pot protocol is proposed (Scheme 3). Based on the control experiments, a plausible reaction mechanism is proposed and depicted in Scheme 4. Our mechanistic investigation was supported by ESI-QTOF-MS technique and collected the mass data at different time intervals with $<5 \mathrm{ppm}$ error. Initially, under copper catalysis substrate 1 gets converted to intermediate I. Next addition of aq. ammonia gives the intermediate II, the observed mass was $[\mathrm{M}+]$ at $\mathrm{m} / \mathrm{z}$ of 198.8620 after $30 \mathrm{~min}$. The replacement of halo atom from the $2^{\text {nd }}$ position with amine will give the intermediate III, the obtained mass result was $[\mathbf{M}+]$ at $m / z$ of 198.8620 . After that another equivalent of aq. ammonia will be addition to the intermediate III to give the intermediate $\mathbf{I V}$, the mass was shown with $[\mathbf{M}+\mathbf{H}]$ at $m / z$ of 216.9222, detected the peak after $1 \mathrm{~h}$, which on further rearrangements gets converted to stable intermediate $\mathbf{V}$, the mass was $[\mathrm{M}+\mathrm{H}]$ at $m / z$ of 137.0021 was observed after $2 \mathrm{~h}$. Intermediate $\mathbf{V}$ on oxidation gets converted into imine intermediate VI which on addition of substituted aldehydes, the mass peak was observed with $[\mathrm{M}+\mathrm{H}]$ at $m / z$ of 225.0094 , gives intermediate VII which finally on oxidation gives the desired products 3a-o in good to moderate yields, for the corresponding product the peak was observed with $[\mathrm{M}+\mathrm{H}]$ at $m / z$ of 223.0896 . The product formation was observed after $6 \mathrm{~h}$ but not completely, further preceding the reaction for 10-12 h to get the complete conversion (Fig. 2).

A series of 2-arylquinazoline derivatives were synthesized with the optimized method as described in Scheme 2. The obtained quinazolinones (3a-f) were further chlorinated using $\mathrm{POCl}_{3}$ and $\mathrm{N}, \mathrm{N}$-diethyl aniline to provide the corresponding 2aryl chloroquinazoline intermediates $\mathbf{4 a - f}$. The chlorinated intermediates $\mathbf{4 a - f}$ were treated with piperazine $\mathbf{5}$ to yield 2-aryl4-(piperazin-1-yl)quinazoline 6a-f. Coupling of $\mathbf{6 a - f}$ with a number of carboxylic acids 7a-i using HATU as coupling reagent afforded the corresponding amide derivatives $\mathbf{8 a - z}$ in moderate to excellent yields. Structures of all the newly synthesized compounds were confirmed by ${ }^{1} \mathrm{H}$ NMR, ${ }^{13} \mathrm{C}$ NMR and HRMS (ESI) spectroscopic techniques (Scheme 5).

The synthesized derivatives were evaluated for their antimicrobial activity against ESKAP pathogen panel (results included in the ESI $\dagger$ ) and Mycobacterium tuberculosis H37Rv strain. ${ }^{\mathbf{1 8 - 2 0}}$ While, the compounds were found to be inactive against ESKAP 


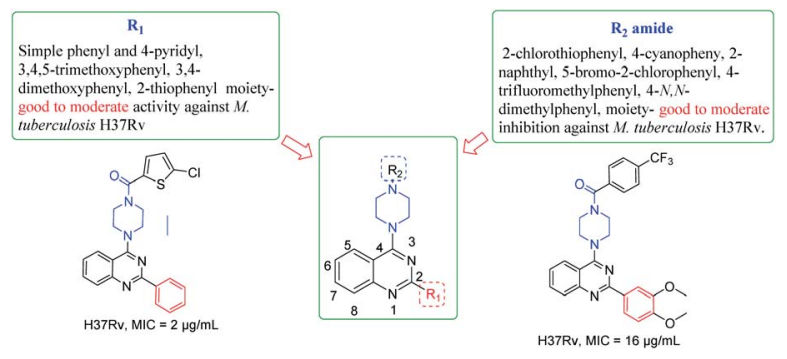

Fig. 3 Structure activity relationship (SAR) of new 2-aryl/heteroaryl quinazoline derivatives.

pathogenic panel, some of the compounds were found to exhibit promising inhibitory activity against $M$. tuberculosis $\mathrm{H} 37 \mathrm{Rv}$ strain (Table 2). A perusal of the results indicated that among the amide derivatives, compounds 8 f exhibited potent anti-mycobacterial activity with MIC of $2 \mu \mathrm{g} \mathrm{mL}^{-1}$ and $8 \mathbf{n}$ showed an MIC of $4 \mu \mathrm{g} \mathrm{mL}{ }^{-1}$. Further, the results indicated that four compounds $\mathbf{8 b}, \mathbf{8 e}, \mathbf{8 m}$ and $\mathbf{8 v}$ showed MIC of $16 \mu \mathrm{g} \mathrm{mL}^{-1}$ whereas other molecules were found to be moderately active or inactive. Presence of methoxy group on 2-phenyl moiety as in 8k and $\mathbf{8 m}$ resulted in moderate activity with MIC of 16-64 $\mu \mathrm{g}$ $\mathrm{mL}^{-1}$. Replacement of C2-phenyl with 4-pyridyl was found to be a favourable lead. Substitution of $\mathrm{R}_{2}$ position with electron withdrawing groups like 2-chloro-5-bromo phenyl 8t showed inhibitory activity with MIC of $32 \mu \mathrm{g} \mathrm{mL}^{-1}$. Compounds having 2-phenyl with electron donating groups like 3,5-dimethoxy and 3,4,5-trimethoxy $\mathbf{8 s}$ and $\mathbf{8 q}$ were found to be inactive but 4- $N, N$ dimethylphenyl was found to be good lead with MIC of $2 \mu \mathrm{g}$ $\mathrm{mL}^{-1}$. Compounds with halogen containing groups like 5bromo-2-chlorophenyl 8y exhibited moderate activity with MIC of $32 \mu \mathrm{g} \mathrm{mL}{ }^{-1}$ whereas 4 -iodo $8 \mathbf{r}$ was inactive and unfortunately rest of the molecules were devoid of activity (Table 2 and Fig. 3).

\section{Conclusions}

In conclusion, we have developed an operationally simple, onepot and cost-efficient method for the preparation of quinazolinones with diverse substituents. This method uses mild catalytic system which enables effective construction of four $\mathrm{C}-\mathrm{N}$ bonds in one pot operation through in situ amine generation, confirmed through the ESI-MS technique. By using the optimised method, we generated a library of new piperazine linked 2-aryl/hetero-aryl-quinazoline derivatives which were evaluated for their anti-microbial activity against ESKAP pathogen panel and also against M. tuberculosis. Among the tested compounds, 8f exhibited selective and potent anti-mycobacterial activity with MIC value $2 \mu \mathrm{g} \mathrm{mL}^{-1}$. Compounds $\mathbf{8 b}, \mathbf{8 e}, \mathbf{8 m}$ and $\mathbf{8 v}$ exhibited moderate anti-mycobacterial activity with MIC value $16 \mu \mathrm{g} \mathrm{mL}{ }^{-1}$. All the synthesized compounds obey the Lipinski rule of $\operatorname{clog} P$ values.

\section{Conflicts of interest}

The authors declare no conflict of interest.

\section{Acknowledgements}

S. M is thankful to Department of Pharmaceuticals, Ministry of Chemicals \& Fertilizers, Govt. of India, for the award of NIPER fellowship. This study was supported by the DST grant from Department of Science and Technology, Govt. of India to S. N. and S. C. (EMR/2017/000220).

\section{Notes and references}

1 K. R. Shreder, M. S. Wong, T. Nomanbhoy, P. S. Leventhal and S. R. Fuller, Org. Lett., 2004, 6, 3715-3718.

2 T. P. Selvam and P. V. Kumar, Res. Pharm., 2011, 1, 1-21.

3 (a) Shagufta and I. Ahmad, MedChemComm, 2017, 8, 871885; (b) M. K. Krapf, J. Gallus and M. Wiese, J. Med. Chem., 2017, 60, 4474-4495.

4 (a) R. P. Modh, E. D. Clercq, C. Pannecouque and K. H. Chikhalia, J. Enzyme Inhib. Med. Chem., 2013, 29, 1475-6374; (b) X. Qi, Y. Li, R. Bai and Y. Lan, Acc. Chem. Res., 2017, 50, 2799-2808.

5 (a) S. Malasala, M. N. Ahmad, J. Gour, M. Shukla, G. Kaul, A. Akhir, S. Gatadi, Y. V. Madhavi, S. Chopra and S. Nanduri, J. Mol. Struct., 2020, 1218, 128493; (b) J. Kunes, B. A. Ant, M. Pour, K. Waisser, S. M. Rek and J. Janota, Il Farmaco, 2000, 55, 725-729; (c) K. M. Srivastav and M. S. Shantakumar, Chem. Sci. Trans., 2013, 2, 1056-1062.

6 (a) S. Gatadi, J. Gour, M. Shukla, G. Kaul, A. Dasgupta, Y. V. Madhavi, S. Chopra and S. Nanduri, Bioorg. Chem., 2018, 83, 569-579; (b) X. X. Guo, D. W. Gu, Z. Wu and W. Zhang, Chem. Rev., 2015, 115, 1622-1651.

7 (a) D. M. Roundhill, Chem. Rev., 1992, 92, 1-27; (b) C. M. Willis, Angew. Chem., Int. Ed., 2007, 46, 3402-3404.

8 (a) F. Lang, D. Zewge, N. I. Houpis and P. R. Volante, Tetrahedron Lett., 2001, 42, 3251-3254; (b) Q. Shen and F. J. Hartwig, J. Am. Chem. Soc., 2006, 128, 10028-10029; (c) V. Lavallo, D. G. Frey, B. Donnadieu, M. Soleihavoup and G. Bertrand, Angew. Chem., Int. Ed., 2008, 47, 5224-5228; (d) C. Gunanathan and D. Milstein, Angew. Chem., Int. Ed., 2008, 47, 8661-8664; (e) D. G. Vo and F. J. Hartwig, J. Am. Chem. Soc., 2009, 131, 11049-11061.

9 (a) S. D. Surry and L. S. Buchwald, J. Am. Chem. Soc., 2007, 129, 10354-10355; (b) J. M. Pouy, A. Leitner, J. D. Weix, S. Ueno and F. J. Hartwig, Org. Lett., 2007, 9, 3949-3952; (c) T. Schulz, C. Torborg, S. Enthaler, B. Schaffner, A. Dumrath, A. Spannenberg, H. Neumann, A. Borner and M. Beller, Chem.-Eur. J., 2009, 15, 4528-4533.

10 D. Zhan, T. Li, H. Wei, W. Weng, K. Ghandi and Q. Zeng, RSC Adv., 2013, 3, 9325-9329.

11 M. U. Hung, B. S. Liao, Y. H. Liu, S. M. Peng and S. T. Liu, Appl. Organomet. Chem., 2014, 28, 661-665.

12 T. Abe, K. Kida and K. Yamada, Chem. Commun., 2017, 53, 4362-4365.

13 C. Ma, C. Q. Zhao, Y. Q. Li, L. P. Zhang, X. T. Xu, K. Zhang and T. S. Mei, Chem. Commun., 2017, 53, 12189-12192.

14 (a) J. C. Palomino and A. Martin, Antibiotics, 2014, 3, 317340; (b) K. Floyd, P. Glaziou, A. Zumla and M. Raviglione, Lancet Respir. Med., 2018, 6, 299-314; (c) G. K. Sandhu, J. 
Global Infect. Dis., 2011, 3, 143-150; (d) S. G. Kurz, J. J. Furin and C. M. Bark, Infect. Dis. Clin. North Am., 2016, 30, 509522.

15 https://www.who.int/en/news-room/fact-sheets/detail/ tuberculosis.

16 (a) V. Dartoisa and C. E. Barry, Bioorg. Med. Chem. Lett., 2013, 23, 4741-4750; (b) S. Chetty, M. Ramesh, A. S. Pillay and M. E. S. Soliman, Bioorg. Med. Chem. Lett., 2017, 27, 370-386. 17 (a) L. Ballell, R. H. Bates, R. J. Young, D. A. Gomez, E. A. Ruiz, V. Barroso, D. Blanco, B. Crespo, J. Escribano, R. S. Lozano, S. Huss, A. S. Villarejo, J. J. Plaza, A. Mendoza, M. R. Lopez, M. R. Blanco, J. L. Lavandera, E. R. Herran, J. F. Benito, J. F. Bustos, D. Barros, J. P. Castro and N. Cammack, ChemMedChem, 2013, 8, 313-321; (b) G. Poce, M. Cocozza, S. Consalvi and M. Biava, Eur. J. Med. Chem., 2014, 86, 335-351; (c) T. Wang, G. Bemis, B. Hanzelka, H. Zuccola, M. Wynn, C. Moody, J. Green, C. Locher, A. Liu, H. Gao, Y. Xu, S. Wang, J. Wang, Y. Bennani, J. Thomson and U. Muh, ACS Med. Chem. Lett., 2017, 8, 1224-1229; (d) T. A. Tran, D. Wen, P. N. West, N. E. Baker, J. W. Britton and J. R. Payne, Org. Biomol. Chem., 2013, 11, 8113-8126;

(e) M. Naik, V. Humnabadkar, S. J. Tantry, M. Panda,
A. Narayan, S. Guptha, V. Panduga, P. Manjrekar, L. K. Jena, K. Koushik, G. Shanbhag, S. Jatheendranath, M. R. Manjunatha, G. Gorai, C. Bathula, S. Rudrapatna, V. Achar, S. Sharma, A. Ambady, N. Hegde, J. Mahadevaswamy, P. Kaur, V. K. Sambandamurthy, D. Awasthy, C. Narayan, S. Ravishankar, S. P. Madhavapeddi, J. Reddy, K. R. Prabhakar, R. Saralaya, M. Chatterji, J. Whiteaker, B. McLaughlin, L. R. Chiarelli, G. Riccardi, M. R. Pasca, C. Binda, J. Neres, N. Dhar, F. S. Gelo, J. D. McKinney, V. Ramachandran, R. Shandil, R. Tommasi, P. S. Iyer, S. Narayanan, V. Hosagrahara, S. Kavanagh, N. Dinesh and S. R. Ghorpade, J. Med. Chem., 2014, 57, 5419-5434.

18 P. A. Wayne, Approved Standard, CLSI document M07-A9, Clinical and Laboratory Standards Institute, 9th edn, 2012.

19 J. H. Jorgensen, J. F. Hindler, L. B. Reller and M. P. Weinstein, Clin. Infect. Dis., 2007, 44, 280-286.

20 (a) M. Pandey, A. K. Singh, R. Thakare, S. Talwar, P. Karaulia, A. Dasgupta, S. Chopra and A. K. Pandey, Sci. Rep., 2017, 7, 11521; (b) I. Wiegand, K. Hilpert and R. E. Hancock, Nat. Protoc., 2008, 3, 163-175. 